IMÁGENES EN CARDIOLOGÍA

\title{
Hemocromatosis secundaria
}

\section{Secondary hemochromatosis}

Emmanuel A. Lazcano-Díaz ${ }^{*}$, Diego X. Chango-Azanza², Zuilma Y. Vásquez-Ortiz, Sandra G. RosalesUvera $^{2}$, Mónica Chapa-Ibargüengoitia ${ }^{2}$, Consuelo Orihuela-Sandoval ${ }^{1}$ y José $P$. Hernández-Reyes ${ }^{1}$

${ }^{1}$ Servicio de Ecocardiografía Clínica; ${ }^{2}$ Servicio de Tomografía Computada y Resonancia Magnética Cardíaca. Instituto Nacional de Ciencias Médicas y Nutrición Salvador Zubirán, Ciudad de México, México

Se presenta el caso de un hombre de 48 años de edad con antecedentes de cuatro años de síndrome mielodisplásico y múltiples transfusiones debido a anemia, que llegó al servicio de urgencias con síntomas de insuficiencia cardíaca de seis semanas de evolución. Los estudios de laboratorios mostraron troponina I de alta sensibilidad de $67 \mathrm{ng} / \mathrm{ml}$, péptido natriurético B de 2,386 pg/ml y ferritina sérica de $4,412 \mathrm{ng} / \mathrm{ml}$. El ecocardiograma transtorácico mostró dilatación de las cuatro cavidades con predominio derecho (Fig. 1A). Las nuevas técnicas de ecocardiografía como la mecánica ventricular con speckle tracking confirmaron una etapa avanzada de miocardiopatía dilatada con disfunción mecánica grave y strain longitudinal de $-10 \%$ (Fig. 1B), circunferencial de $7.7 \%$ y radial de $16 \%$; resultó interesante el twist negativo de $-7^{\circ}$ (Fig. 1C) por inversión de la dirección del giro basal y apical. La resonancia magnética cardíaca mostró dilatación y disfunción biventricular grave, con fracción de expulsión ventricular izquierda de $22 \%$ y derecha de $27 \%$. Se sospechó miocardiopatía por infiltración de hierro debida a sus antecedentes, por lo que se realizó resonancia magnética cardíaca con secuencia de $\mathrm{T}^{*}$, que confirmó infiltración moderada de hierro cardíaco con un valor de $17 \mathrm{~ms}$ y un valor hepático $\mathrm{T}^{*}$ de $27 \mathrm{~ms}$ (Fig. 1D). El realce tardío con gadolinio en el eje corto mostró fibrosis difusa de predominio epicárdico (Fig. 1E). Estos hallazgos son característicos del fenotipo dilatado de la miocardiopatía infiltrativa por hierro (hemocromatosis) en etapas avanzadas de la enfermedad.

\section{Financiamiento}

Ninguno.

\section{Conflicto de intereses}

Los autores declaran no tener conflicto de intereses. DOI: $10.24875 / A C M .20000411$ 


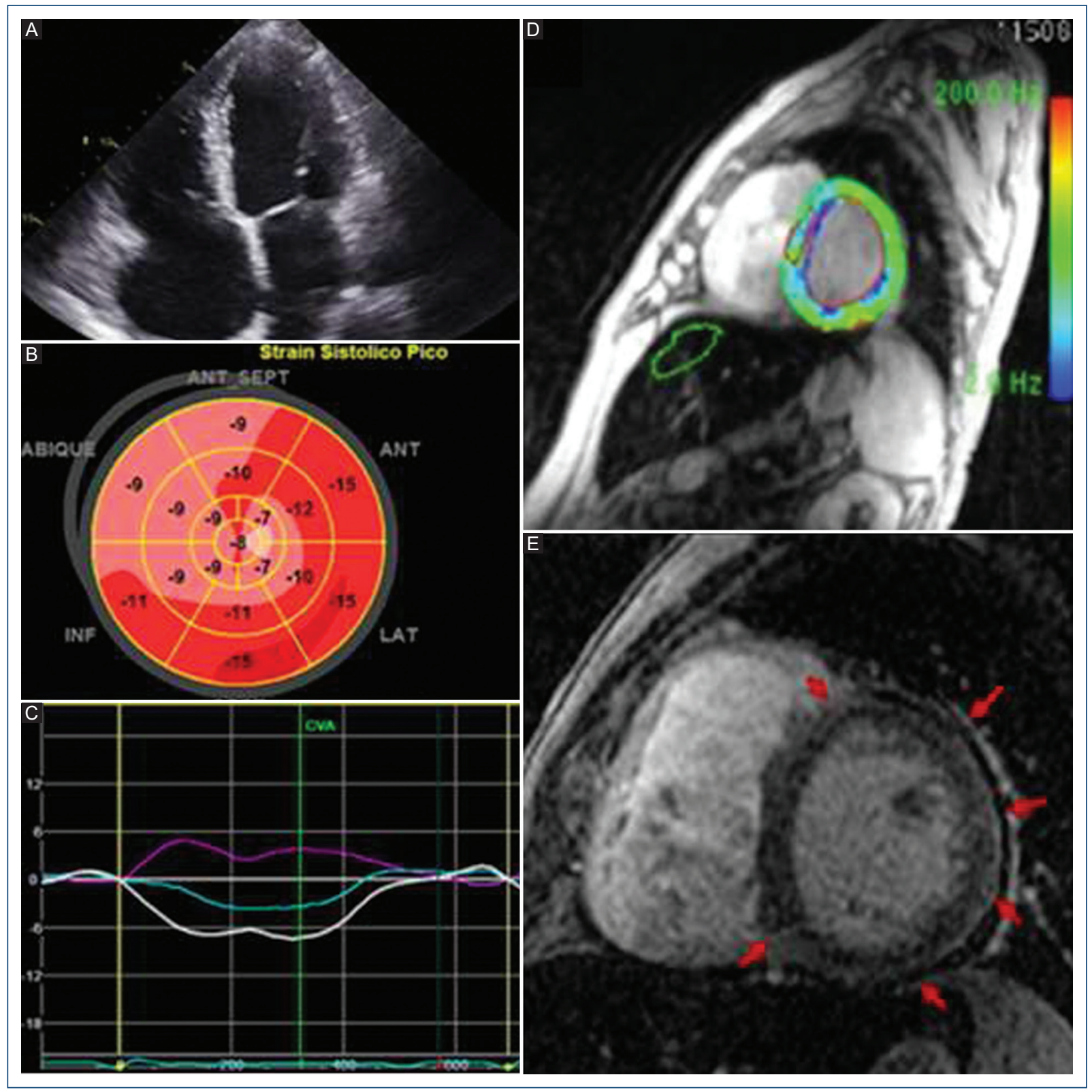

Figura 1. A: Ecocardiograma transtorácico: vista apical de cuatro cámaras. B: Mapa polar que muestra disminución del strain longitudinal global. C: Inversión del twist (línea blanca) con valor negativo (-7%). D: Secuencia de resonancia magnética cardíaca en $\mathrm{T}^{*}$ en el eje corto a nivel de la base que confirma miocardiopatía infiltrativa por hierro. E: Realce tardío con gadolinio a nivel del eje corto que muestra fibrosis de predominio epicárdico (flechas rojas).

\section{Responsabilidades éticas}

Protección de personas y animales. Los autores declaran que para esta investigación no se han realizado experimentos en seres humanos ni en animales.
Confidencialidad de los datos. Los autores declaran que en este artículo no aparecen datos de pacientes.

\section{Derecho a la privacidad y consentimiento infor-}

mado. Los autores declaran que en este artículo no aparecen datos de pacientes. 